\title{
The influence of poly(2-methoxyaniline-5-sulfonic acid) on the electrochemical and photochemical properties of a highly luminescent ruthenium complex
}

\author{
Lynn Dennany ${ }^{\mathrm{a}, \mathrm{b}}$, Emmet J. O’Reilly ${ }^{\mathrm{a}}$, Peter C. Innis ${ }^{\mathrm{b}}$, \\ Gordon G. Wallace ${ }^{\mathrm{b}}$, Robert J. Forster ${ }^{\mathrm{a}, *}$ \\ ${ }^{a}$ Biomedical Diagnostics Institute, National Centre for Sensor Research, School of Chemical Sciences, \\ Dublin City University, Dublin 9, Ireland \\ ${ }^{\mathrm{b}}$ ARC Centre of Excellence for Electromaterials Science and Intelligent Polymer Research Institute, \\ University of Wollongong, Northfields Avenue, Wollongong, NSW, Australia
}

Received 26 September 2007; received in revised form 7 November 2007; accepted 11 November 2007 Available online 19 November 2007

\begin{abstract}
Immobilisation of a luminescent material on an electrode surface is well known to substantially modulate its photophysical and electrochemical properties. Here a positively charged ruthenium metal complex $\left(\left[\mathrm{Ru}(\mathrm{bpy})_{3}\right]^{2+}\right)$ is immobilised on all electrode surface by ion paring with a sulfonated conducting polymer poly(2-methoxyaniline-5-sulfonic acid), (PMAS). Significantly, our study reveals that the electron transport between the ruthenium metal centres can be greatly enhanced due to the interaction with the conducting polymer when both are surface confined. Charge transfer diffusion rates in the present system are an order of magnitude faster than those found where the metal centre is immobilised within a non-conducting polymeric matrix. Electron transport appears to be mediated through the PMAS conjugated structure, contrasting with the electron hopping process typically observed in non-conducting metallopolymers. This increased regeneration rate causes the ruthenium-based electrochemiluminescence (ECL) efficiency to be increased. The impact of these observations on the ECL detection of low concentrations of disease biomarkers is discussed.
\end{abstract}

(C) 2007 Published by Elsevier Ltd.

Keywords: Electrochemiluminescence; Conducting polymers; Luminescence; $\mathrm{Ru}(\mathrm{bpy})_{3}{ }^{2+}$; Electropolymerisation

\section{Introduction}

Chemically modified electrodes have been of interest because of their potential in electrocatalysis and other applications where deliberate control of the electrode-solution interface is desirable. The use of polymers as supports for confining transition metals at the electrode-solution interface is well known [1,2]. Polypyrroles containing coordinated metal complexes are an attractive approach to forming interfacial metallopolymer films since the $\pi$ conjugated backbone can provide a rapid electron transfer pathway between the metal complex and the electrode [2-5]. Here we explore an alternative approach that simply involves the incorporation of the ruthenium metal centre by

\footnotetext{
* Corresponding author. Tel.: +353 1 7005943; fax: +3531 7005503 .

E-mail address: Robert.Forster@dcu.ie (R.J. Forster).
}

ion pairing with sulfonate groups of poly(2-methoxyaniline-5sulfonic acid), (PMAS).

Sulfonated self-doped polyaniline has been extensively studied due to its unique electrochemical properties, water solubility, improved processability and potential industrial applications [6-8]. PMAS is a fully sulfonated conducting polymer that has been synthesised by chemical and electrochemical polymerisation of 2-methoxyaniline 5-sulfonic acid, MAS [9,10]. In-depth characterisation of the electrochemical and photochemical properties of these two distinctive fractions have also been reported [11].

The ability of conjugated linkages to provide an effective pathway for the electron transfer between metal centres has been demonstrated in a number of polymeric systems. Zotti et al. [12] have shown that electron transfer rates between metal centres in substituted polythiophenes, with pendant ferrocene moieties, is enhanced when a conjugated linkage is used. 
Cameron and Pickup [4,5] have also shown that coordination of ruthenium moieties to a conjugated polybenzimidazole provides a rapid electron transfer pathway by superexchange interactions between metal centres. However, this increased electron transfer did not translate into enhanced luminescence of the ruthenium moiety, presumably due to the energy/electron transfer processes from the excited state of the metal complex to the polymer represents a competing radiationless decay pathway.

Significantly, PMAS can form novel composites via the anionic $\mathrm{SO}_{3}{ }^{-}$functionality ion pairing with the cationic $\left[\mathrm{Ru}(\mathrm{bpy})_{3}\right]^{2+}$ fluorophore. Earlier studies have focused upon luminescent $\left[\mathrm{Ru}(\mathrm{bpy})_{2}\right]^{2+}$ moieties covalently bound to a poly(4-vinyl-pyridine) backbone at statistical separations of the order of $50 \AA$ [13]. Unlike these PVP-based metallopolymers, the PMAS- $\left[\mathrm{Ru}(\mathrm{bpy})_{3}\right]^{2+}$ composites offer greater synthetic flexibility as well as increased charge transport rates due to both physical diffusion and the electronically conducting properties of the backbone. These properties uniquely enable the development of advanced diagnostic devices based on the luminescent detection of analytes including proteins and DNA biomarkers since more rapid electrochemical production of the $\mathrm{Ru}^{3+}$ state ought to produce a greater total emission intensity per unit time [14]. ECL represents a powerful analytical approach that combines simple equipment with inherent sensitivity, selectivity, and a wide linear dynamic range for amine containing analytes, such as alkylamines, NADH, hydrazine, amino acids, biomolecules and a variety of pharmaceutical compounds [15-19]. ECL usually involves the reaction of electrogenerated species that react to form excited states, usually via an energetic redox reaction [19]. Thus, ECL can also be utilised to probe electron and energy transfer processes at electrified interfaces [20,21]. Consequently, increasing and improving the ECL efficiency could advance the sensitivity ranges and expand the dynamic range of current ECL systems.

We have recently reported that oxidation of guanines in DNA by electrochemically generated $\left[\mathrm{Ru}(\mathrm{bpy})_{2}(\mathrm{PVP})_{10}\right]^{2+}$ in ultrathin films leads to photoexcited $\left[\mathrm{Ru}(\mathrm{bpy})_{2}\right]^{2+*}$ sites in the film, generating an ECL signal upon relaxation back to the ground state [22]. This thin-film ECL approach has been exploited to detect DNA damage induced by styrene oxide. The reaction was initiated by an electrochemical catalytic oxidation of guanine sites in DNA in a way that is similar to that reported by Thorp and co-workers [23] for $\mathrm{Ru}(\mathrm{bpy}) 3^{2+}$ in solution. By enhancing the ECL or luminescent efficiency of the ruthenium moiety through interactions with a conducting polymer, the sensitivity of this type of ECL sensors could be dramatically improved. Within this contribution, however, we will focus on the production of light from the reaction of ruthenium metal centres with oxalate, similar to that described by Hogan and co-workers [13,24].

It is known that when $\left[\mathrm{Ru}(\mathrm{bpy})_{3}\right]^{2+}$ is oxidized in a solution containing $\mathrm{C}_{2} \mathrm{O}_{4}{ }^{2-}$ the following reaction takes place and ECL is observed $[25,26]$ :

$$
\begin{aligned}
& \mathrm{Ru}(\text { bpy })_{3}{ }^{2+} \rightarrow \mathrm{Ru}(\text { bpy })_{3}{ }^{3+}+\mathrm{e}^{-} \\
& \mathrm{Ru}(\text { bpy })_{3}{ }^{3+}+\mathrm{C}_{2} \mathrm{O}_{4}{ }^{2-} \rightarrow \mathrm{Ru}(\text { bpy })_{3}{ }^{2+}+\mathrm{CO}_{2}+\mathrm{CO}_{2}{ }^{-}- \\
& \mathrm{Ru}(\text { bpy })_{3}{ }^{2+}+\mathrm{CO}_{2}{ }^{-} \rightarrow \mathrm{Ru}(\text { bpy })_{3}{ }^{+}+\mathrm{CO}_{2}
\end{aligned}
$$

$$
\begin{aligned}
& \mathrm{Ru}(\text { bpy })_{3}{ }^{3+}+\mathrm{Ru}(\text { bpy })_{3}{ }^{+} \rightarrow \mathrm{Ru}(\text { bpy })_{3}{ }^{2+*}+\mathrm{Ru}(\text { bpy })_{3}{ }^{2+} \\
& \mathrm{Ru}(\text { bpy })_{3}{ }^{3+}+\mathrm{CO}_{2}{ }^{-} \rightarrow \mathrm{Ru}(\text { bpy })_{3}{ }^{2+*}+\mathrm{CO}_{2} \\
& \mathrm{Ru}(\text { bpy })_{3}{ }^{2+*} \rightarrow \mathrm{Ru}(\text { bpy })_{3}{ }^{2+}+h v
\end{aligned}
$$

Similar processes occur within metallopolymer films deposited on metallic electrodes containing pendant $\mathrm{Ru}(\mathrm{bpy})_{2}{ }^{2+}$ centres [13]. The $\left[\mathrm{Ru}(\mathrm{bpy})_{2}(\mathrm{PVP})_{10}\right]^{2+}$ films contain ruthenium centres that are electrochemically isolated, while in a PMAS-Ru(bpy) ${ }_{2}{ }^{2+}$ composite an electrochemically active backbone provides a mechanism for communication between adjacent ruthenium centres absence in the systems discussed above. The effect of an electronically conducting polymer on the ECL response, charge transport and photochemical properties of a metal centre are examined in this contribution.

\section{Experimental}

\subsection{Materials and reagents}

$\left[\mathrm{Ru}(\mathrm{bpy})_{3}\right]^{2+}$ was synthesised according to a literature method [27]. The metallopolymer, $\left[\mathrm{Ru}(\mathrm{bpy})_{2} \mathrm{PVP}_{10}\right]\left(\mathrm{ClO}_{4}\right)_{2}$, was prepared as described previously [28]. PMAS synthesis has been reported previously for both chemical and electrochemical synthesis methods [9]. MAS was provided by Mitsubishi Rayon, Japan and purified by acid base crystallisation before polymerisation.

\subsection{Apparatus}

Absorbance and photo-luminescence were recorded using a Shimadzu UV-1601 spectrophotometer and a JY Spex fluorescence spectrophotometer, respectively. Fluorescence lifetime studies were made on a PicoQuant PDL-800B pulsed diode laser controller and FluoTime 100 time-correlated single photon counting system (TCSPC) with 280, 370 and $450 \mathrm{~nm}$ pulsed laser sources with cut-on filters of 400, 475 and $530 \mathrm{~nm}$. TCSPC analysis was preformed using PicoQuant FluoFit software. Samples were deoxygenated for approximately $20 \mathrm{~min}$ with nitrogen prior to analysis. All other electrochemical experiments were carried out using a 3 or $2 \mathrm{~mm}$ diameter platinum or glassy carbon working electrode in a conventional three-electrode assembly. Potentials are quoted versus $\mathrm{Ag} / \mathrm{AgCl}$ and all measurements were made at room temperature.

Cyclic voltammetry analysis was made with a $\mathrm{CH}$ Instruments Model 660 electrochemical analyser. All potentials were made with respect to a $3 \mathrm{M} \mathrm{Ag} / \mathrm{AgCl}$ reference electrode unless otherwise stated. Measurements involving simultaneous detection of light and current utilised a model 273 (Princeton) potentiostat and an Oriel 70680 photomultiplier tube (PMT) equipped with a high voltage power supply, (Oriel, model $70705)$, which was used at a bias of $-850 \mathrm{~V}$, and amplifier/recorder (Oriel, model 70701). During experiments the cell was placed inside a specially constructed holder, where the working electrode is positioned in a reproducible manner directly opposite the face of a fibre optic bundle, the other end of which was coupled to the PMT. The entire electrode assem- 
bly was contained inside a light-tight box. Acquisition, handling and display of the signals from the potentiostat and PMT were achieved using a data acquisition card (National instruments Lab-PC-1200) and a custom programme written in Labview ${ }^{\mathrm{TM}}$.

Scanning electron microscopy (SEM) was performed using a Hitachi S-3000N variable pressure system. All images were recorded at a chamber pressure of $20 \mathrm{~Pa}$ and accelerating voltages of 5-20 kV were employed. Energy dispersive X-ray, EDX, analysis was also performed.

\subsection{Composite synthesis}

Electropolymerisation of the Ru-PMAS composite was preformed by cyclic voltammetry over a potential range of -200 to $1300 \mathrm{mV}$, at a scan rate of $50 \mathrm{mV} \mathrm{s}^{-1}$, which involves the in situ oxidation of the MAS and growth on subsequent cycles, for a minimum of 10 cycles. Electrosynthesis was performed in an electrolyte that contained $5 \mathrm{mM}$ MAS monomer, $\mathrm{pH}$ 4.4 , and $2 \mathrm{mM}\left[\mathrm{Ru}(\mathrm{bpy})_{3}\right]^{2+}$. Films were electrodeposited onto $\mathrm{Pt}$, glassy carbon, or ITO working electrodes. These modified electrodes were then washed (Milli-Q water) and allowed to dry overnight prior to analysis. Post synthesis characterisation was performed in $0.1 \mathrm{M} \mathrm{H}_{2} \mathrm{SO}_{4}$ solution unless otherwise stated. Surface coverages of the composite films, $\Gamma$, were determined by graphical integration of background corrected cyclic voltammograms $\left(<5 \mathrm{mV} \mathrm{s}^{-1}\right)$. The surface coverage varied from $(2.0 \pm 4.2) \times 10^{-9}$ to $(6.9 \pm 4.2) \times 10^{-9} \mathrm{~mol} \mathrm{~cm}^{-2}$.

For comparison purposes, thin films of $\left[\mathrm{Ru}(\mathrm{bpy})_{2}(\mathrm{PVP})_{10}\right]^{2+}$ were prepared by drop casting. Where appropriate, working electrodes were modified by applying a drop $(\approx 200 \mu \mathrm{L}$ to ITO electrode and $\sim 30 \mu \mathrm{L}$ onto a glassy carbon electrode) of a $1.0 \%$ ethanolic solutions of $\left[\mathrm{Ru}(\mathrm{bpy})_{2}(\mathrm{PVP})_{10}\right]^{2+}$, with typical surface coverages of $(2.4 \pm 0.7) \times 10^{-9} \mathrm{~mol} \mathrm{~cm}^{-2}$.

\section{Results and discussion}

\subsection{Electrochemical properties of the novel $\left[R u(\text { bpy })_{3}\right]^{2+}$-PMAS composites}

Electrochemically polymerised $\mathrm{Ru}-\mathrm{PMAS}$ films were visibly uniform. Similarly uniform films are obtained by evaporating controlled volumes of a $1 \%(\mathrm{w} / \mathrm{v})$ solution of $[\mathrm{Ru}$ $\left.(\mathrm{bpy})_{2}(\mathrm{PVP})_{10}\right]^{2+}$ from ethanol on to glassy carbon electrode. Typical cyclic voltammograms obtained for composite films of $\left[\mathrm{Ru}(\mathrm{bpy})_{2}(\mathrm{PVP})_{10}\right]^{2+}$ and Ru-PMAS following composite film formation versus $\mathrm{Ag} / \mathrm{AgCl}$ are shown in Fig. 1. The voltammetric behaviour of PMAS has been reported previously [10], as have with independent studies characterising PVP films containing ruthenium moieties [22]. Surface coverages, $\Gamma$, were calculated by graphical integration of background corrected peaks associated with the $\mathrm{Ru}^{2+/ 3+}$ process at approximately $1.1 \mathrm{~V}$ [29] using slow scan rates $\left(<5 \mathrm{mV} \mathrm{s}^{-1}\right)$. For the $\mathrm{Ru}-\mathrm{PMAS}$ composite, $\Gamma$ was $(6.9 \pm 4.2) \times 10^{-9} \mathrm{~mol} \mathrm{~cm}^{-2}$, while for the $\left[\mathrm{Ru}(\mathrm{bpy})_{2}(\mathrm{PVP})_{10}\right]^{2+}$ film it was $(2.0 \pm 1.0) \times 10^{-9} \mathrm{~mol} \mathrm{~cm}^{-2}$.

The formal potential of both the $\mathrm{Ru}^{2+/ 3+}$ couple are shown in Table 1. PMAS exhibited typical anodic and cathodic behaviour, which were attributed to leucoemeraldine to emeraldine and

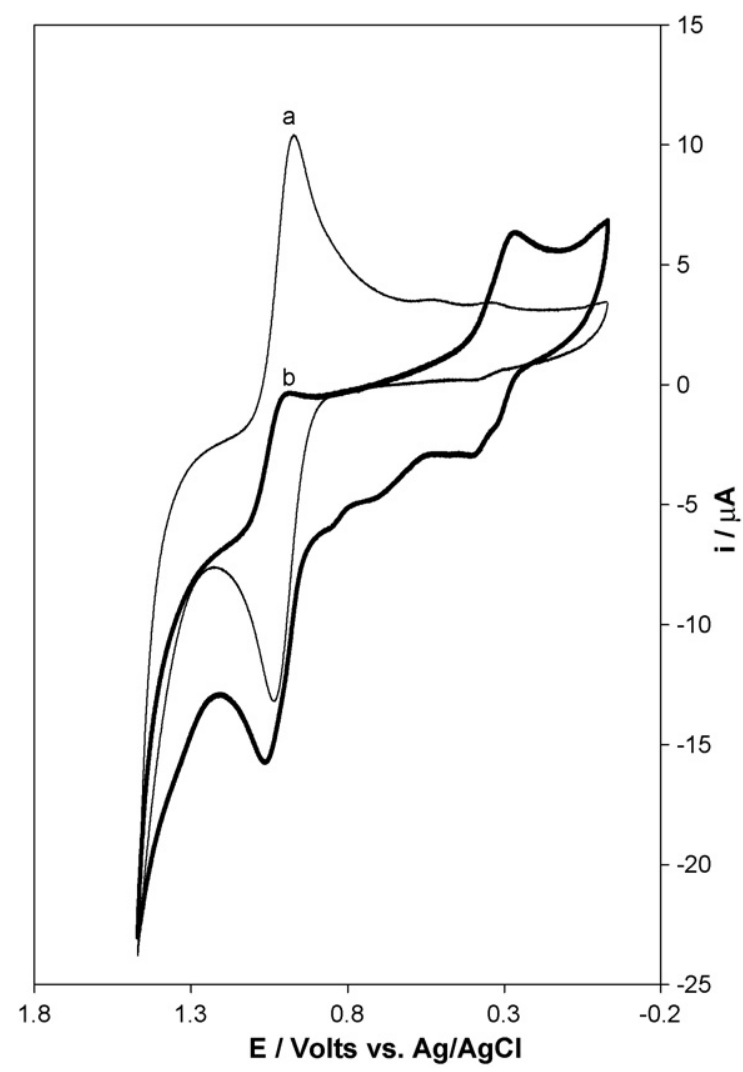

Fig. 1. Typical cyclic voltammograms of thin films of, (a) $\left[\mathrm{Ru}(\mathrm{bpy})_{2}(\mathrm{PVP})_{10}\right]^{2+}$ and (b), Ru-PMAS following film formation on glassy carbon electrodes. Electrolyte was $0.1 \mathrm{M} \mathrm{H}_{2} \mathrm{SO}_{4}$, and a scan rate of $100 \mathrm{mV} \mathrm{s}^{-1}$ was used. The surface coverages were $(2.4 \pm 0.7) \times 10^{-9} \mathrm{~mol} \mathrm{~cm}^{-2}$ for the $\left[\mathrm{Ru}(\mathrm{bpy})_{2}(\mathrm{PVP})_{10}\right]^{2+}$ film and $(2.0 \pm 4.2) \times 10^{-9}$ to $(6.9 \pm 4.2) \times 10^{-9} \mathrm{~mol} \mathrm{~cm}^{-2}$ for the Ru-PMAS composite. Cyclic voltammograms were recorded over the range $-0.1 \leq E$ (volts) $\geq 1.4$ with the $\mathrm{CV}$ starting at $-0.1 \mathrm{~V}$.

emeraldine to pernigraniline redox transitions, respectively. However, the redox transitions were not resoluble when the films were grown in the presence of the ruthenium complex.

The ruthenium peak current in the PMAS composites varied linearly with scan rate, $v$, up to $30 \mathrm{mV} \mathrm{s}^{-1}$ indicating that the response was controlled by finite charge transport diffusion on these long timescales. At shorter experimental timescales, i.e., at scan rates between 100 and $500 \mathrm{mV} \mathrm{s}^{-1}$, the thickness of the depletion layer was smaller than the film thickness and the peak current varied linearly with the square root of scan rate, as shown in Fig. 2. It was also evident that at lower scan rates, the peak-to-peak separation, $\Delta E_{\mathrm{p}}$, did not become zero. This behaviour has been previously observed for related mono-

Table 1

Typical formal potentials and diffusion coefficients, $D_{\mathrm{ct}}$, of the various ruthenium films used during this study

\begin{tabular}{lll}
\hline Composite & $D_{\text {ct }}\left(\mathrm{cm}^{2} \mathrm{~s}^{-1}\right)$ & $E^{0}\left(\mathrm{Ru}^{2+/ 3+}\right) V$ vs. Ag/AgCl \\
\hline$\left[\mathrm{Ru}(\mathrm{bpy})_{2}(\mathrm{PVP})_{10}\right]^{2+\mathrm{a}}$ & $1.68 \times 10^{-9}$ & 1.19 \\
{$\left[\mathrm{Ru}(\mathrm{bpy})_{2}(\mathrm{PVP})_{10}\right]^{2+}$} & $1.16 \times 10^{-11}$ & 1.05 \\
Ru-PMAS & $3.11 \times 10^{-10}$ & 1.02
\end{tabular}

$0.1 \mathrm{M} \mathrm{H}_{2} \mathrm{SO}_{4}$ was used as supporting electrolyte.

a The values quoted here are for solution phase results. 


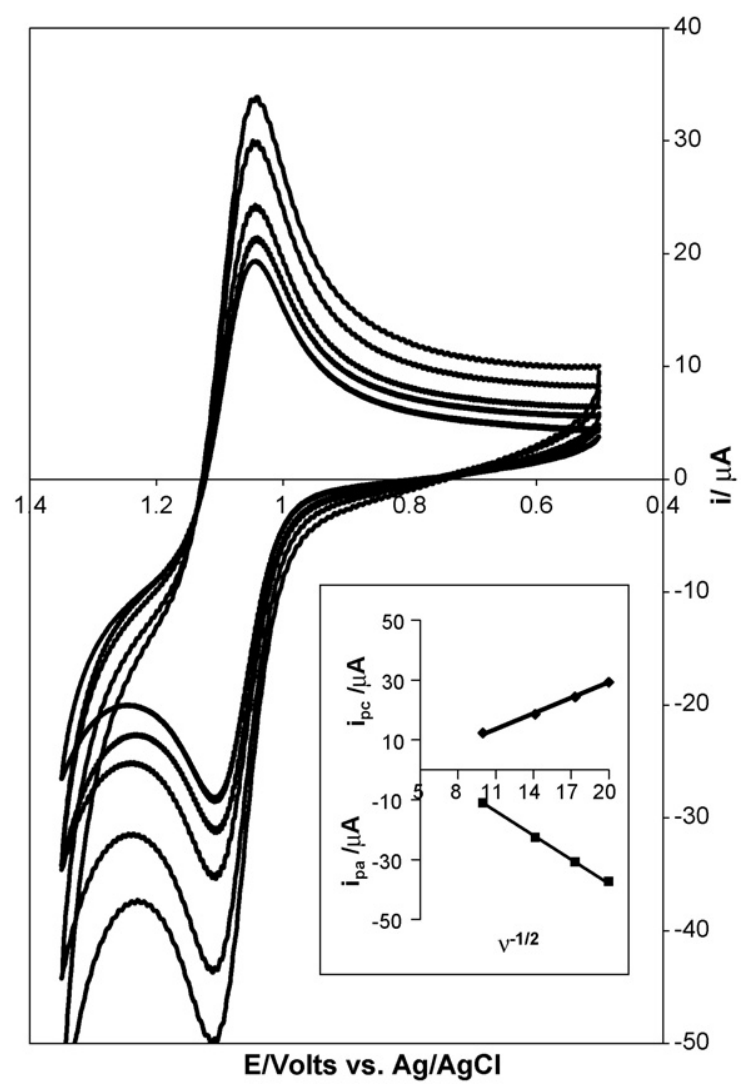

Fig. 2. Scan rate dependency for Ru-PMAS, $\left(\Gamma=(2.0 \pm 4.2) \times 10^{-9}\right.$ to $\left.(6.9 \pm 4.2) \times 10^{-9} \mathrm{~mol} \mathrm{~cm}^{-2}\right)$, in $0.1 \mathrm{M} \mathrm{H}_{2} \mathrm{SO}_{4}, 100<v<500 \mathrm{mV} \mathrm{s}^{-1}$. Insert shows Randles-Sevich plot for this data, after background corrections had been preformed on each individual cyclic voltammogram to remove the background current.

layers [30] and thin polymer films [24,31,32] and most likely arises from unusual quasi-reversibility [33]. For both the PVP and PMAS systems, the full width at half-maximum (FWHM) was close to the theoretical value of $90.6 \mathrm{mV}$ typical of a reaction involving the transfer of a single electron. However, some "diffusional" tailing was also evident. While the response appeared to be influenced by both finite and semi-infinite linear diffusion control, the results were indicative that the ruthenium moiety could be electrochemically reversibly cycled.

\subsection{Electron transfer processes within the composites}

The sensitivity of an ECL sensor was dictated in part by the rate at which the $\mathrm{Ru}^{3+}$ sites are regenerated within the film. The rate of charge movement through the film is characterised by the charge transport apparent diffusion coefficient, $D_{\text {ct. }}$. This parameter can be obtained from a plot of $i_{\mathrm{p}}$ versus $v^{1 / 2}$ under semi-infinite linear diffusion controlled conditions. This response is described by the Randles-Sevcik equation, (Eq. (7)):

$i_{\mathrm{p}}=2.69 \times 10^{5} n^{3 / 2} A D_{\mathrm{ct}}^{1 / 2} v^{1 / 2} C$

Electron transport in redox polymers has been shown to occur via at least three mechanisms [34]. Where the backbone in nonconducting, outer-sphere electron exchange between redox sites provides the only significant contribution to electron transport
[35,36]. In highly conjugated systems, electron transport can also occur through the polymer backbone by mediated and/or superexchange mechanisms [37]. These are distinguished by the availability of redox states within the polymer that have suitable energy to mediate electron transport. If such states are available, the electron can hop between a localised metal-based redox site, a polymer-based site, and a second metal site in two steps (mediated mechanism). If these states are not accessible, then electron transfer through the backbone must result from a mixing of appropriate orbitals of both metals with the HOMO and/or LUMO of the backbone (superexchange). Although the ruthenium metal centre was not coordinated to the PMAS backbone, the conducting backbone may play a similar role in electron transport within the composite structure. Importantly, PMAS is in its electronically conducting form at the formal potential of the Ru couple, making mediated electron transfer process the most likely mechanism. In all cases, plots of $i_{\mathrm{p}}$ versus $v^{1 / 2}$ were linear and $D_{\mathrm{ct}}$ values were obtained from the slopes according to Eq. (7) using a ruthenium concentration of $0.6 \mathrm{M}$.

Table 1 contains the $D_{\mathrm{ct}}$ values for the PMAS composite and the $\left[\mathrm{Ru}(\mathrm{bpy})_{2} \mathrm{PVP}_{10}\right]^{2+}$ metallopolymer. This table shows that the diffusion coefficient calculated for the ruthenium redox couple with the composite is approximately an order of magnitude larger $\left((3.1 \pm 0.8) \times 10^{-10} \mathrm{~cm}^{2} \mathrm{~s}^{-1}\right)$ than that found for the PVP-based system $\left((1.2 \pm 0.4) \times 10^{-11} \mathrm{~cm}^{2} \mathrm{~s}^{-1}\right)$.

Based on a maximum fixed site concentration of $0.6 \mathrm{M}$, the minimum dry film thickness $(\delta)$, was approximately $2 \times 10^{-9} \mathrm{~mol} \mathrm{~cm}^{-2}$. Using the homogeneous charge transport diffusion coefficient in conjunction with the Eq. (8) indicated that the time taken to fully oxidize the layer and regenerate the $\mathrm{Ru}^{3+}$ mediating centres was approximately $10 \mathrm{~s}$ for a $\left[\mathrm{Ru}(\mathrm{bpy})_{2}(\mathrm{PVP})_{10}\right]^{2+}$ film and $5 \mathrm{~s}$ for the PMAS composite films.

$t=\frac{\delta^{2}}{\pi D_{\mathrm{CT}}}$

This faster regeneration of the $\mathrm{Ru}^{3+}$ species in the composite may lead to a more intense ECL generation and hence a lower limit of detection.

\subsection{Steady state luminescence of composites}

Typical emission responses of PMAS, $\left[\mathrm{Ru}(\mathrm{bpy})_{2}(\mathrm{PVP})_{10}\right]^{2+}$ and the composite film when excited at $355 \mathrm{~nm}$ are shown in Fig. 3. It is important to note that the Ru composition of the films was analysed by EDX and the emission normalized for the \%ruthenium metal centres present in the composite films. Significantly, the Ru-PMAS composite exhibits emission at approximately 610 and $520 \mathrm{~nm}$, i.e., both a ruthenium and substantially weaker PMAS-based emission are observed. This observation indicates that efficient energy transfer from the PMAS to ruthenium does not occur suggesting weak interaction between the two components in the excited state. Moreover, the Ru-based emission with the PMAS composite was significantly lower than that found for the PVP-based metallopolymer. This observation is surprising given that the excited state lifetime of 


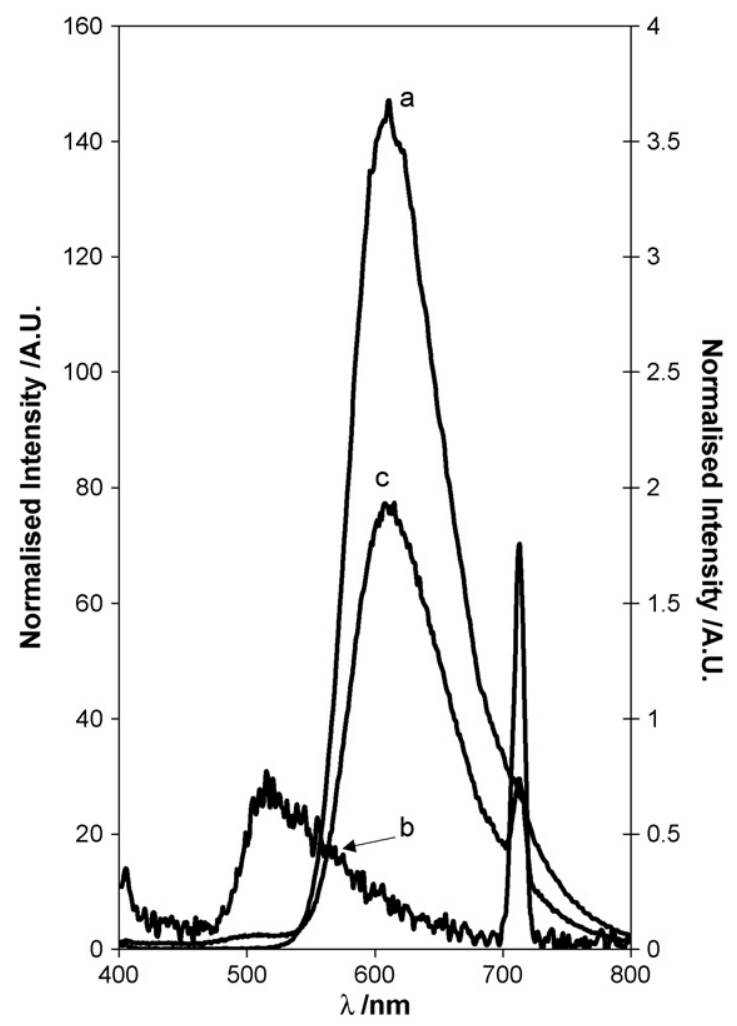

Fig. 3. Typical luminescence spectra for thin films of (a) $\left[\mathrm{Ru}(\mathrm{bpy})_{2}(\mathrm{PVP})_{10}\right]^{2+}$, (b) PMAS and (c) Ru-PMAS on ITO electrodes. An excitation wavelength of $355 \mathrm{~nm}$ was utilised. (a) and (c) relate to the primary axis while the other plot, (b), is against the secondary axis. The surface coverages were all approximately $(4.9 \pm 1.2) \times 10^{-9} \mathrm{~mol} \mathrm{~cm}^{-2}$.

the $\left[\mathrm{Ru}(\mathrm{bpy})_{3}\right]^{2+}$ moiety is approximately three times longer than the $\left[\mathrm{Ru}(\mathrm{bpy})_{2} \mathrm{PVP}_{10}\right]^{2+}$ luminophore. This behaviour may arise due to the strong absorbance by the PMAS at the excitation wavelength of $355 \mathrm{~nm}$ [38]. Alternatively, the PMAS may act as an electron transfer quencher of the ruthenium excited state.

\subsection{Luminescence lifetimes of composites}

The luminescent lifetime can provide useful insights into the structure of the metallopolymer film and on the excited state electron transfer processes, e.g., $\mathrm{Ru}^{2+*}+\mathrm{Ru}^{3+} \rightarrow \mathrm{Ru}^{3+}+\mathrm{Ru}^{2+}$. Fig. 4 illustrates emission transients obtained using TCSPC for thin films of $\left[\mathrm{Ru}(\mathrm{bpy})_{2}(\mathrm{PVP})_{10}\right]^{2+}$, and the Ru-PMAS fractions $\left(\Gamma=(2.1 \pm 0.2) \times 10^{-9} \mathrm{~mol} \mathrm{~cm}^{-2}\right)$ deposited on ITO electrodes in contact with $0.1 \mathrm{M} \mathrm{H}_{2} \mathrm{SO}_{4}$, following excitation at $355 \mathrm{~nm}$ with the emission detection centred at $620 \mathrm{~nm}$. In contrast, to the single exponential decays observed for the metallopolymer dissolved in solution, thin films of both the PVP metallopolymer and PMAS composite exhibit a more complex decay characterised by least two time-constants. For the $\left[\mathrm{Ru}(\mathrm{bpy})_{2}(\mathrm{PVP})_{10}\right]^{2+}$ film, the luminescent decay was characterised by short and long-lived components that have lifetimes of $170 \pm 9$ (population fraction of 0.7 ) and $65 \pm 6 \mathrm{~ns}$ (population fraction of 0.3$)$, respectively. The $\left[\mathrm{Ru}(\mathrm{bpy})_{3}\right]^{2+}$ complex dissolved in solution also exhibits a single exponential decay

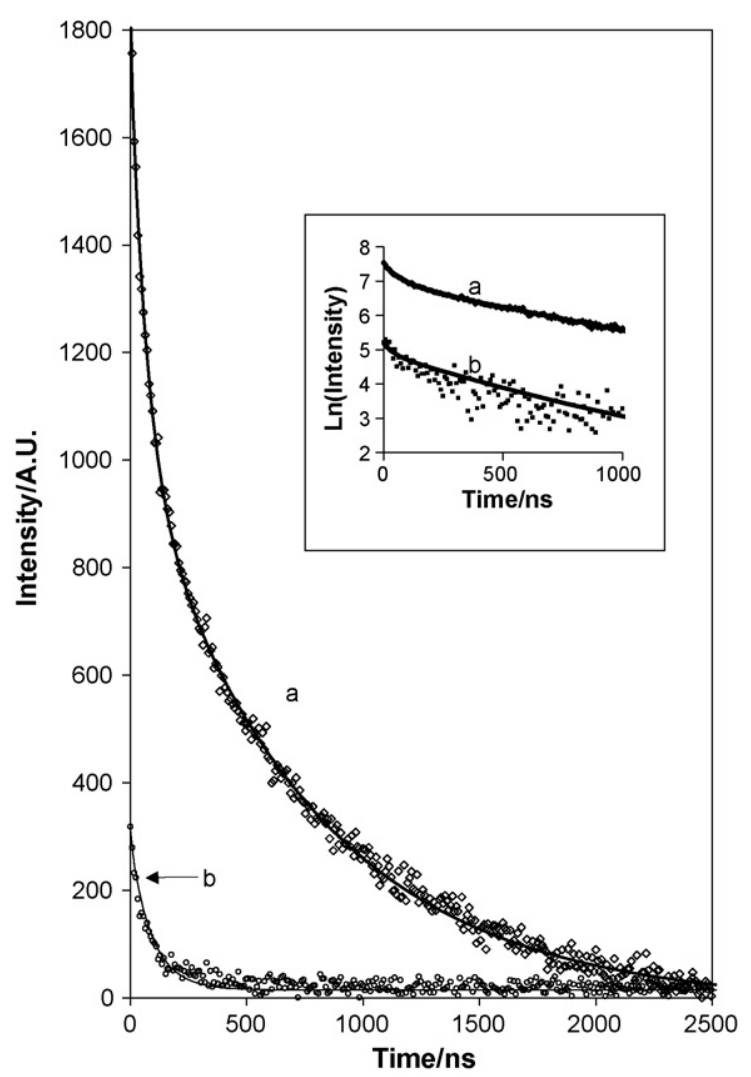

Fig. 4. Typical transient emission spectra for thin films of (a) $[\mathrm{Ru}$ (bpy) $\left.)_{2}(\mathrm{PVP})_{10}\right]^{2+}$ and (b) electrochemically grown Ru-PMAS on ITO electrodes. An excitation wavelength of $370 \mathrm{~nm}$ was utilised. The insert shows the corresponding semi-log intensity vs. time plots. The surface coverages were all approximately $(4.9 \pm 1.2) \times 10^{-9} \mathrm{~mol} \mathrm{~cm}^{-2}$.

of $\sim 625 \mathrm{~ns}$. When immobilised within PMAS, $\left[\mathrm{Ru}(\mathrm{bpy})_{3}\right]^{2+}$ exhibits double exponential decay behaviour and consistent with its reduced emissions, the lifetime of the longest-lived component is almost an order of magnitude smaller than that found for the complex in solution. The percentage amplitude of the separate components and the luminescence decays of the ruthenium composite films are shown in Table 2. The reduced lifetime of $\left[\mathrm{Ru}(\mathrm{bpy})_{3}\right]^{2+}$ within PMAS was entirely consistent with quenching of the luminophore by the conducting polymer backbone. This observation is important for the development of ECL sensors since the presence of the PMAS leads to a faster turnover of the $\mathrm{Ru}^{3+}$ species that ultimately leads to emission after interacting with a suitable co-reactant such as guanine, tripropyl amine or oxalate. However, a decreased lifetime will directly affect

Table 2

Typical excited state lifetimes, $\tau$, for the various ruthenium films used during this study

\begin{tabular}{lcl}
\hline Composite & $\tau_{1}(\mathrm{~ns})\left(\% \tau_{1}\right)$ & $\tau_{2}(\mathrm{~ns})\left(\% \tau_{2}\right)$ \\
\hline$\left[\mathrm{Ru}(\mathrm{bpy})_{2}(\mathrm{PVP})_{10}\right]^{2+\mathrm{a}}$ & 365 & \\
{$\left[\mathrm{Ru}(\mathrm{bpy})_{2}(\mathrm{PVP})_{10}\right]^{2+}$} & $170(70)$ & $65(30)$ \\
$\mathrm{Ru}-\mathrm{PMAS}$ & $69(40)$ & $22(60)$ \\
\hline
\end{tabular}

The percentage amplitude for each of the components of the lifetime is also shown.

a The values quoted here are for solution phase results. 


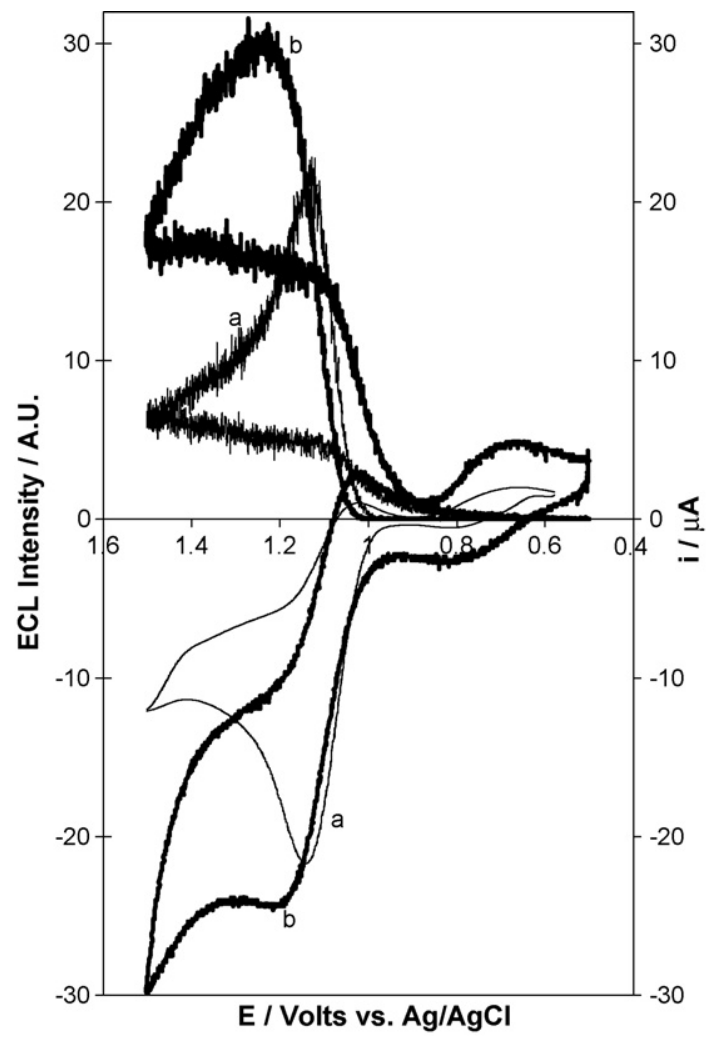

Fig. 5. Potential dependence of current and emission intensity of (a) $[\mathrm{Ru}$ (bpy $\left.)_{2}(\mathrm{PVP})_{10}\right]^{2+}$ modified electrode and (b) Ru-PMAS composite modified electrode in $0.4 \mathrm{M} \mathrm{Na}_{2} \mathrm{SO}_{4}$ solution containing $50 \mathrm{mM} \mathrm{Na}_{2} \mathrm{C}_{2} \mathrm{O}_{4}$ (pH 4.7). Scan rate of $100 \mathrm{mV} \mathrm{s}^{-1}$. The surface coverages were $(2.4 \pm 0.7) \times 10^{-9} \mathrm{~mol} \mathrm{~cm}^{-2}$ for the $\left[\mathrm{Ru}(\mathrm{bpy})_{2}(\mathrm{PVP})_{10}\right]^{2+}$ film and $(2.0 \pm 4.2) \times 10^{-9}$ for the Ru-PMAS composite.

the emission intensity but may be useful for some applications since it will reduce the sensitivity of the material to oxygen quenching.

\subsection{Electrochemiluminescence properties of composite films}

Fig. 5 illustrates the potential dependent current and emission intensity responses for the PVP and PMAS modified electrodes in $0.1 \mathrm{M} \mathrm{H}_{2} \mathrm{SO}_{4}$ solution containing $10 \mathrm{mM} \mathrm{Na}_{2} \mathrm{C}_{2} \mathrm{O}_{4}(\mathrm{pH} 4.7)$ as the co-reactant. At the unmodified electrode, anodic current was observed to flow at potentials more positive than $+1.15 \mathrm{~V}$. This value was significantly more positive than the standard redox potential of oxalic acid of $-555 \mathrm{mV}$ under equivalent conditions [39]. For both systems the current response centred at $+1.16 \mathrm{~V}$ and was significantly enhanced compared to that observed at the bare working electrode or at a modified working electrode in the absence of oxalic acid. The observed current enhancement was a direct result of the mediated oxidation of oxalic acid by $\mathrm{Ru}^{3+}$ centres within the film.

For the modified electrodes, the onset of light emission coincided closely with the onset of oxidative current at the potential where the $\mathrm{Ru}^{3+}$ species was generated. This behaviour was consistent with oxalate reducing the electrogenerated $\mathrm{Ru}^{3+}$ species to the excited state reduced product $\mathrm{Ru}^{2+*}$ which then relaxes to the electronic ground state via emission (Eqs. (1)-(6)). Despite the optically induced emission being weaker for the PMAS than for the PVP system, the PMAS produces the most intense ECL emission intensity. This behaviour arises because ECL does not suffer from the self-absorbance observed in the optically driven emission investigations presented in Fig. 3. The increase in ECL intensity of the PMAS composite compared to the PVP-based metallopolymer arises from the ability of PMAS to facilitate faster production of $\mathrm{Ru}^{3+}$ within the film.

However, the enhancement was not as great as expected given the observed $D_{\text {ct }}$. This may, in part, be due to non-uniform distribution of $\mathrm{Ru}$ centres within the composite structure. Closely packed Ru centres may quench the emission via a self-quenching mechanism, previously described for $\left[\mathrm{Ru}(\mathrm{bpy})_{2}(\mathrm{PVP})_{10}\right]^{2+}$ films whereby this effect was minimized by the synthetic procedure [13]. Further investigations into the growth of the $\mathrm{Ru}-\mathrm{PMAS}$ composite films will provide additional insight to develop methodologies for minimizing self-quenching.

\section{Conclusion}

A novel composite between the electronically conducting polymer, poly(2-methoxyaniline-5-sulfonic acid) and $\left[\mathrm{Ru}(\mathrm{bpy})_{3}\right]^{2+}$ is reported. Cyclic voltammetry and emission investigations reveal that while the PMAS supports more rapid charge propagation within the composite, self-absorbance and electron transfer quenching cause the optically driven emission to be weaker than in a model metallopolymer, $\left[\mathrm{Ru}(\mathrm{bpy})_{2} \mathrm{PVP}_{10}\right]^{2+}$ where the polymer backbone is nonconducting. Significantly, ECL investigations reveal that the enhanced electron transport between ruthenium metal centres within the PMAS composite produces an enhanced ECL emission. This result highlights a key issue in the design of ECL-based sensors in that the ECL intensity is controlled by a series of interlinked processes and that changing the properties of one component, e.g., the polymer backbone by increasing the efficiency of one aspect while decreasing another.

\section{Acknowledgements}

The financial support of Science Foundation Ireland under the Biomedical Diagnostics Institute (Award No. 05/CE3/B754) is deeply appreciated, Continued financial support from the Australian Research Council Centres of Excellence and QE(II) Fellowship (Innis) programmes is greatly appreciated.

\section{References}

[1] S. Cosnier, Biosensors Bioelectron. 14 (1999) 443

[2] P.G. Pickup, J. Mater. Chem. 9 (1999) 1641.

[3] J. Ochmanska, P.G. Pickup, J. Electroanal. Chem. 271 (1989) 83.

[4] C.G. Cameron, P.G. Pickup, Chem. Commun. 3 (1997) 303.

[5] C.G. Cameron, P.G. Pickup, J. Am. Chem. Soc. 121 (1999) 7710.

[6] D. Zhou, P.C. Innis, G.G. Wallace, S. Shimizu, S.-I. Maeda, Synth. Metals 114 (2000) 287.

[7] S. Shimizu, T. Saitoh, M. Uzawa, M. Yuasa, K. Yano, T. Maruyama, K. Watanabe, Synth. Metals 85 (1997) 1337. 
[8] X.-L. Wei, Y.Z. Wang, S.M. Long, C. Bobeczko, A.J. Epstein, J. Am. Chem. Soc. 118 (1996) 2545.

[9] F. Masdarolomoor, P.C. Innis, S. Ashraf, G.G. Wallace, in: ICSM 2004, Wollongong, Australia, 2004.

[10] F. Masdarolomoor, P.C. Innis, S. Ashraf, G.G. Wallace, Synth. Metals 153 (2005) 181.

[11] F. Masdarolomoor, P.C. Innis, S. Ashraf, R.B. Kaner, G.G. Wallace, Marcomol. Rapid Commun. 27 (2006) 1995

[12] G. Zotti, G. Schiavon, S. Zecchin, A. Berlin, G. Pagani, A. Canavesi, Synth. Metals 76 (1996) 255.

[13] L. Dennany, C.F. Hogan, T.E. Keyes, R.J. Forster, Anal. Chem. 78 (2006) 1412.

[14] J.G. Velasco, Electroluminescence Electroanal. 3 (1991) 261.

[15] J.B. Noffsinger, N.D. Danielson, Anal. Chem. 59 (1987) 865.

[16] S.N. Brune, D.R. Bobbitt, Anal. Chem. 64 (1992) 166.

[17] A.W. Knight, G.M. Greenway, Analyst 121 (1996) 101R.

[18] W.-Y. Lee, Mikrochim. Acta 127 (1997) 19.

[19] A.J. Bard, L.R. Faulkner, Electrochemical Methods: Fundamentals and Applications, second ed., Wiley, New York, 2001.

[20] L.R. Faulkner, A.J. Bard, Electroanalytical Chemistry, Marcel Dekker, New York, 1977, p. 1

[21] A.W. Knight, G.M. Greenway, Analyst 119 (1994) 879.

[22] L. Dennany, R.J. Forster, J.F. Rusling, J. Am. Chem. Soc. 125 (2003) 5213.
[23] D.H. Johnston, K.C. Glasgow, H.H. Thorp, J. Am. Chem. Soc. 117 (1995) 8933.

[24] C.F. Hogan, R.J. Forster, Anal. Chim. Acta 396 (1999) 13.

[25] X. Zhang, A.J. Bard, J. Phys. Chem. 92 (1988) 5566.

[26] I. Rubinstein, A.J. Bard, J. Am. Chem. Soc. 103 (1981) 5007.

[27] J.V. Caspar, T.J. Meyer, J. Am. Chem. Soc. 105 (1983) 5583.

[28] A.P. Clarke, PhD, Dublin City University, Dublin, 1991, Ch. 3.

[29] N.E. Tokel, A.J. Bard, J. Am. Chem. Soc. 94 (1972) 2862.

[30] R.J. Forster, J.L. Brennan, T.E. Keyes, Langmuir 22 (2006) 10754.

[31] R.J. Forster, D. Walsh, N. Mano, F. Mao, A.J. Heller, Langmuir 20 (2004) 862.

[32] R.J. Forster, C.F. Hogan, Anal. Chem. 72 (2000) 5576.

[33] S.W. Feldberg, I. Rubinstein, J. Electroanal. Chem. 240 (1988) 1.

[34] R.A. Denny, M.V. Sangaranarayanan, J. Phys. Chem. B 102 (1998) 8670.

[35] M.E.G. Lyons, in: M.E.G. Lyons (Ed.), In Electroanalytical Chemistry Part I: Fundamentals, Plenum Press, New York, 1994, p. 89.

[36] G. Inzelt, in: A.J. Bard (Ed.), Electroanalytical Chemistry, 18, Marcel Dekker, New York, 1994, p. 89

[37] M.-A. Haga, M. Ali, S. Koseki, A. Yoshimura, K. Nozaki, T. Ohno, Inorg. Chim. Acta 226 (1994) 17.

[38] P.C. Innis, F. Masdarolomoor, L.A.P. Kane-Maguire, R.J. Forster, T.E. Keyes, G.G. Wallace, J. Phys. Chem. B 111 (2007) 12738.

[39] K. Binran, Japan Chemical Society, third ed., Maruzen, 1984. 